\title{
Chemoselective Polycondensation of 2-Amino-4,6-dichloro-1,3,5-triazine with Aromatic Diamines
}

\author{
Yuji Shibasaki, ${ }^{* 1}$ Takanori Koizumi, ${ }^{1}$ Naoya Nishimura, ${ }^{2}$ and Yoshiyuki Oishi ${ }^{1}$ \\ ${ }^{1}$ Department of Chemistry and Bioengineering, Graduate School of Engineering, Iwate University, \\ 4-3-5 Ueda, Morioka, Iwate 020-8551 \\ ${ }^{2}$ Synthesis Research Department, Chemical Research Laboratory, Nissan Chemical Industries, Ltd., \\ 722-1 Tsuboi-cho, Funabashi, Chiba 274-8507
}

(Received July 25, 2011; CL-110627; E-mail: yshibasa@iwate-u.ac.jp)

\begin{abstract}
Chemoselective polycondensation of 2-amino-4,6-dichloro1,3,5-triazine (ADCT) was investigated with various aromatic diamines such as 4,4'-oxydianiline (ODA), 9,9-bis(4-aminophenyl)fluorene (BAFL), 4,4'-(hexafluoropropane-2,2-diyl)dianiline (BisAF), and bis(4-aminophenyl)sulfone (SODA) in the presence of potassium carbonate as a base. High-molecular weight perfectly linear polyguanamines $\left(M_{\mathrm{n}} \approx 46000\right)$ were successfully obtained for the polycondensation of ADCT with BisAF, while the polycondensation of ADCT with BAFL afforded branched polyguanamines with a degree of branching of from 0.02 to 0.17 .
\end{abstract}

Chemoselective reactions, many of which can be observed in living organisms, are key techniques in the construction of complex structures from polyfunctional components. The basic strategy for chemoselective reaction is the utilization of the different reactivity in like functional groups such as between aliphatic amines and aromatic amines. Various types of the chemoselective reactions are applied to the preparation of polymers such as polythiophenes, ${ }^{1,2}$ polyesters, ${ }^{3}$ and polyamides. ${ }^{4}$ Such controlled reaction affords regioregular structures, resulting in a variety of higher-ordered polymeric architectures.

Triazine is an aromatic molecule having three nitrogen atoms. Its derivatives are commonly prepared from cyanuric chloride, and used for dyes, ${ }^{5}$ fluorescent brightening agents, ${ }^{6}$ and agrochemicals. ${ }^{7}$ When a monofunctional compound is introduced into cyanuric chloride, the resulting compounds can be used as difunctional triazine-based monomers for the preparation of polyguanamines, ${ }^{8,9}$ polyethers, ${ }^{10}$ and polythioethers. ${ }^{11}$ The interest in polymers that incorporate the amino-s-triazine moiety is the existence of the strong interaction between polymer main chains via hydrogen bonding, ${ }^{12}$ numerous reactive sites along with the polymer backbone to modify the polymer, or the application to photopolymers. Therefore, 2-amino-4,6-dichloro1,3,5-triazine (ADCT), the monomer of the amino-s-triazine functional polymer has been extensively studied. ${ }^{13}$ However, polycondensation of ADCT with difunctional monomers could afford branching structure, resulting in low-molecular weight polymers, or gelation. Because aromatic diamines have less nucleophilicity than their aliphatic counterparts, polymerization of ADCT with aromatic diamines were expected to instantly form a gel. To the best of our knowledge, no report has been published about the chemoselective polycondensation of ADCT with aromatic diamines to date, although the expected polymers would show interesting reactivity toward electrophiles due to the numerous regularly-aligned amino groups on the polymer backbone. Here we report the polymerization of ADCT with

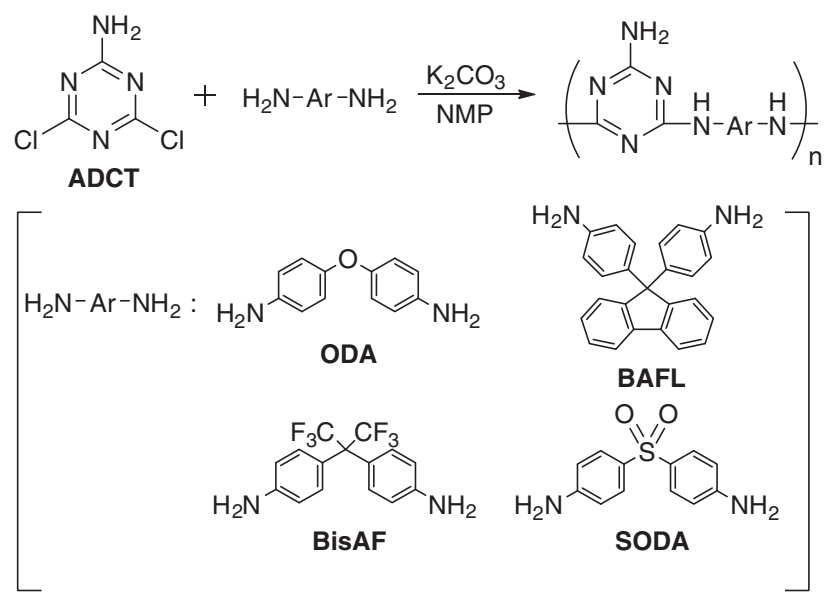

Scheme 1. Synthesis of polyguanamines from ADCT with various aromatic diamines.

Table 1. Summary of polyguanamine synthesis ${ }^{\mathrm{a}}$

\begin{tabular}{clrrrrrr}
\hline Run & \multirow{2}{*}{ Diamine } & $\begin{array}{c}\text { Temp } \\
/{ }^{\circ} \mathrm{C}\end{array}$ & $\begin{array}{c}\text { Time } \\
/ \mathrm{h}\end{array}$ & $\begin{array}{c}\text { Yield }^{\mathrm{b}} \\
/ \%\end{array}$ & $M_{\mathrm{n}}^{\mathrm{c}}$ & $M_{\mathrm{w}} / M_{\mathrm{n}}{ }^{\mathrm{c}}$ & $M_{\mathrm{n}(\mathrm{NMR})}{ }^{\mathrm{d}}$ \\
\hline 1 & ODA & 150 & 3 & $>99$ & 1500 & 18 & 1900 \\
2 & BAFL & 150 & 3 & 80 & 3600 & 8.8 & 4000 \\
3 & BAFL & 150 & 24 & 61 & 14000 & 2.3 & 14000 \\
4 & BAFL & 180 & 24 & 59 & 19000 & 10.5 & 20000 \\
5 & BisAF & 150 & 3 & 88 & 1000 & 32 & 1300 \\
6 & BisAF & 180 & 12 & 33 & 46000 & 2.3 & 37000 \\
7 & SODA & 150 & 3 & 50 & - & - & - \\
\hline
\end{tabular}

${ }^{\mathrm{a} C}$ Conditions: $2.5 \mathrm{mmol}$ of ADCT, $2.5 \mathrm{mmol}$ of diamine monomer, $5.5 \mathrm{mmol}$ of $\mathrm{K}_{2} \mathrm{CO}_{3}$ in $5 \mathrm{~mL}$ of NMP. ${ }^{\text {b }}$ Methanolinsoluble part. ${ }^{\mathrm{c}}$ Determined by GPC (NMP containing $0.01 \mathrm{~mol} \mathrm{~L}^{-1}$ of LiBr). ${ }^{\mathrm{d}}$ Determined by NMR.

various aromatic diamines involving ODA, BAFL, BisAF, and SODA, and the evaluation of the chemoselectivity.

Polycondensation of ADCT with aromatic diamines was performed in $N$-methylpyrrolidinone (NMP) in the presence of potassium carbonate as base as shown in Scheme 1 (see the Supporting Information about the detail of the experimental procedures ${ }^{14}$ ). The results of the polymerization are summarized in Table 1 . When the polycondensation was conducted using ODA as a diamine monomer at $150^{\circ} \mathrm{C}$ for $3 \mathrm{~h}$, the polymerization solution became heterogeneous to form a low-molecularweight polymer (Run 1). On the other hand, the polymerization with BAFL or BisAF afforded soluble high-molecular-weight polymers. However, in the case of the polymerization using 
BAFL at $180^{\circ} \mathrm{C}$, a larger polydispersity ratio polymer was obtained, which indicates the formation of branching structure (Run 4). Since the polymer with reasonable polydispersity ratio was obtained by the polymerization of ADCT with BisAF even at $180^{\circ} \mathrm{C}$, higher chemoselectivity seemed to be attained in this case (Run 6). The GPC profile of the as-made polymeric solution from ADCT with BisAF was a bimodal distribution, indicating the formation of cyclic oligomers. Thus, the yield of the polymer was relatively low. Polymerization hardly proceeded for ADCT with SODA due to the poor solubility of the resulting polymer (Run 7).

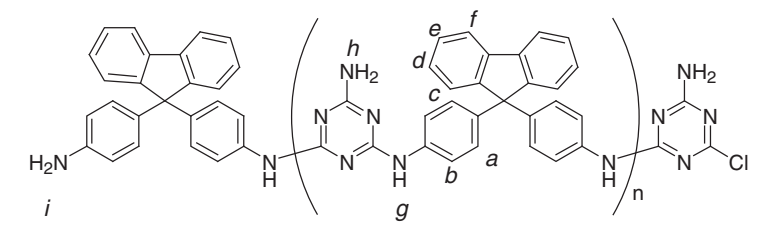

$$
\text { a) } 150{ }^{\circ} \mathrm{C}, 24 \mathrm{~h}
$$$$
\text { a }
$$
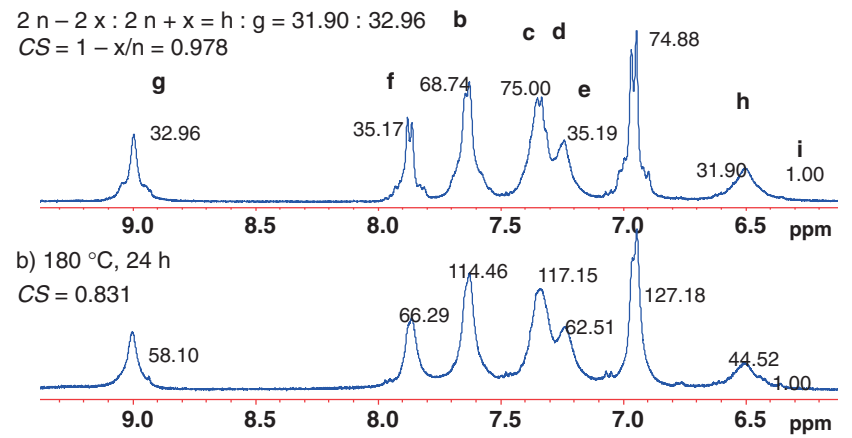

Figure 1. Expanded ${ }^{1} \mathrm{HNMR}$ spectra of polyguanamines from ADCT with BAFL at a) 150 and b) $180^{\circ} \mathrm{C}$ for $24 \mathrm{~h}$.

Figure 1 depicts the expanded ${ }^{1} \mathrm{HNMR}$ spectra of the polymers obtained from ADCT with BAFL at a) 150 and b) $180^{\circ} \mathrm{C}$ for $24 \mathrm{~h}$. In addition to the signals assignable to protons of the polymer main chain segment, a signal assignable to terminal amino proton $(i)$ is observed at $6.4 \mathrm{ppm}$. These were assigned from the ${ }^{1} \mathrm{HNMR}$ signals of the monomers and 2-amino-6-chloro-4-(4-methoxyanilino)-1,3,5-triazine (ADCTAN) model compound. The molecular weights estimated from

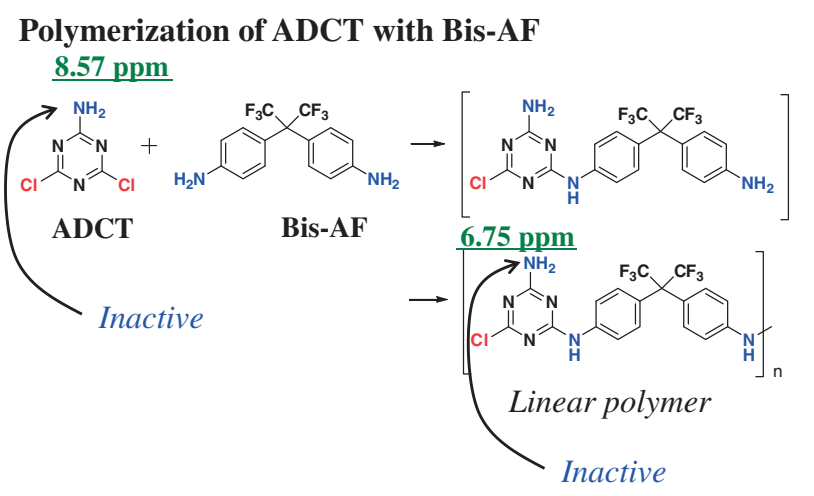

Polymerization of ADCT with ODA or BAFL

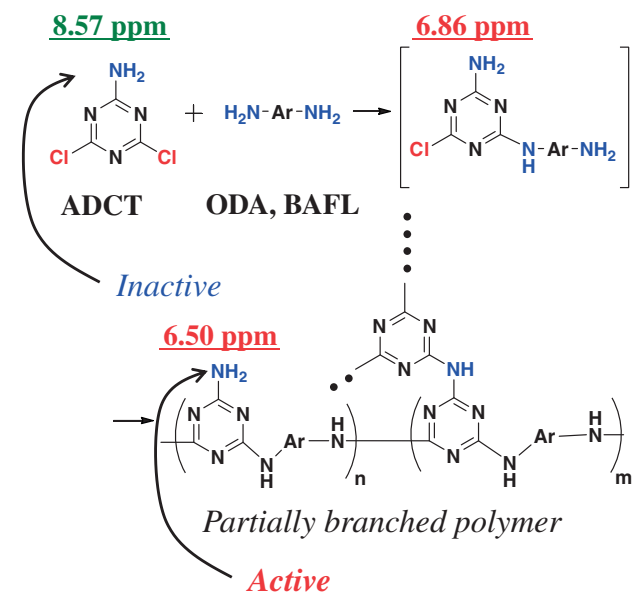

Figure 2. Plausible mechanism in polyguanamine synthesis.

the integration values of protons $(i)$ and $(f)$ in ${ }^{1} \mathrm{HNMR}$ spectra show good agreement with those from GPC measurements. The chemoselectivity $(C S)$ of the polymerization was estimated from the following equation, in which $n$ is the degree of polymerization and $x$ is the number of branching.

$$
C S=1-x / n
$$

These two parameters $n$ and $x$ can be correlated with the integrations in the ${ }^{1} \mathrm{HNMR}$ spectrum as follows;

(Number of hydrogens in $\left.\mathrm{NH}_{2}\right)$ :(Number of hydrogens in guanamine) $=(2 n-2 x):(2 n+x)=h: g$

Thus, the $C S$ can be calculated to be 0.978 and 0.831 for a) and b), respectively. From these results, higher polymerization temperature of ADCT with BAFL resulted in branched structure in the polymer architecture.

The $C S$ for the polymer from ADCT with BisAF was nearly 1 even at $180^{\circ} \mathrm{C}$ polymerization (Run 6). We initially expected that the branching could be formed as a result of the competitive condensation between dichloride in ADCT with diamines and amine groups in ADCT, but the experimental results were in complete disagreement; higher $C S$ was achieved in the case of diamine monomer with lower nucleophilicity, BisAF. Thus, in order to know the reactivity of the amino function in the ADCT segment before and after the polymerization, ${ }^{1} \mathrm{H}$ NMR spectrum of the intermediate model compound ADCT-AN, which was obtained from ADCT with $p$-anisidine, was measured. As shown in Figure 2, the chemical shifts of the amino groups in ADCT and ADCT-AN were at 8.57 and $6.86 \mathrm{ppm}$, respectively. After the polymerization with BisAF, the amino protons appeared at $6.75 \mathrm{ppm}$. In the case of the polymerization with BAFL, these protons shifted further upfield to $6.50 \mathrm{ppm}$. At $150{ }^{\circ} \mathrm{C}$, the amino function of ADCT segment in the polymer backbone was almost inactive for the condensation with chlorotriazine moiety, but it can react at $180^{\circ} \mathrm{C}$ to afford branching structures. Because the amino group in the ADCT-BisAF polymer has lower electron density due to the strong inductive effect of six fluorine atoms, there is almost no branching in ADCT-BisAF polymerization even at $180^{\circ} \mathrm{C}$.

As the thermal properties of the resulting polymers, we measured the glass transitions $\left(T_{\mathrm{g}}\right)$ by differential scanning calorimetry (DSC) and 5\%-weight-loss temperatures $\left(T_{\mathrm{d} 5}\right)$ by 
thermogravimetry under nitrogen. The $T_{\mathrm{g}}$ and the $T_{\mathrm{d} 5}$ were 266 and 477 for ADCT-BAFL (Run 3), and 121 and $488^{\circ} \mathrm{C}$ for ADCT-BisAF polymer samples (Run 6), respectively. The bulky pendant fluorene group as well as the stiffness of the aromatic polyguanamine backbone gave rise to the high thermostability of the ADCT-BAFL polymer sample. Thus, the reason for the lower $T_{\mathrm{g}}$ of the ADCT-BisAF polymer sample could be attributed to the flexible hexafluoropropane-2,2-diyl group.

In conclusion, polycondensation of ADCT with various aromatic amines was investigated in an aprotic polar solvent, and it is revealed that the chemoselectivity of the polymerization was affected by the nucleophilicity of the amino group in the ADCT segment after the polymerization. These changes of the reactivity of the amino group along the polymer chains would be useful for the design of linear to hyperbranched architecture in polyguanamine synthesis.

This study was supported by the Foundation for Japanese Chemical Research.

\section{References and Notes}

1 R. D. McCullough, R. D. Lowe, J. Chem. Soc., Chem. Commun. 1992, 70.

2 T. A. Chen, R. D. Rieke, J. Am. Chem. Soc. 1992, 114, 10087.

3 A. Takasu, Y. Shibata, Y. Narukawa, T. Hirabayashi,
Macromolecules 2007, 40, 151.

4 M. Ueda, A. Kameyama, K. Hashimoto, Macromolecules 1988, 21, 19.

5 H. Zollinger, Color Chemistry: Syntheses, Properties, and Applications of Organic Dyes and Pigments, 2nd ed., VCH, Weinheim, New York, Basel, Cambridge, 1991.

6 R. Anliker, G. Muller, Fluorescence Whitening Agents in Environmental Qualty and Safety, Thieme, Stuttgart, 1975, Suppl. Vol. IV.

7 J. A. Best, J. B. Oberacker, Weed Sci. 1974, 22, 364.

8 D. F. Kutepov, N. N. Kogan, Vysokomol. Soedin., Ser. B 1970, 12, 344.

9 Y. Oishi, T. Suzuki, H. Awano, K. Yonetake, IEEE Trans. Appl. Supercond. 2004, 14, 1604.

10 L. A. Koroleva, L. A. Rodivilova, M. S. Akutin, Vysokomol. Soedin., Ser. B 1973, 15, 923.

11 S. Kondo, H. Mori, M. Kadomatsu, K. Sato, T. Ando, T. Kakuno, H. Kunisada, Y. Yuki, J. Macromol. Sci., Part A: Pure Appl. Chem. 1996, 33, 811.

12 M. B. Steffensen, E. Hollink, F. Kuschel, M. Bauer, E. E. Simanek, J. Polym. Sci., Part A: Polym. Chem. 2006, 44, 3411 .

13 N. Irles, J. Puiggalí, J. A. Subirana, Macromol. Chem. Phys. 2001, 202, 3316.

14 Supporting Information is available electronically on the CSJ-Journal Web site, http://www.csj.jp/journals/chem-lett/ index.html. 